\title{
O lugar da Oceanografia
}

\section{AFRANNIO RUBENS DE MESQUTTA}

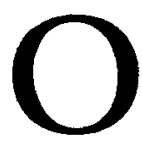

$s$ registros históricos de conhecimentos sobre os oceanos, feitos na antigüidade, se relacionaram com as qualidades pistpeis dos oceanos, isto $e$, forma, salinidade, temperatura, correntes, ondas, mares, organismos vivos, sedimentos, entre outros, que são parâmetros naturalmente nominados, entre os tópicos estudados modernamente, como linhas de pesquisa. As causas utilizadas para explicar os fenômenos descritos seguiam os modelos aceitos da época. Quanto à forma, o oceano era plano e terminava abruptamente em algum lugar e a variação semidiurna do nível do mar (mares) era devida à respiraçáo de um grande monstro a habitar as profundezas marinhas. A variação térmica, as ondas, os sedimentos tinham o sol, os ventos, os sedimentos transportados da terra ao mar como os responsáveis... os valores salinos e as correntes eram mais difíceis de entender, enquanto os peixes, muito bem utilizados na alimentaçáo e no comércio, eram explicados como postos a serviço da sobrevipencia bumana.

A partir do Renascimento a forma dos oceanos foi conhecida (continentes e pólos), a lei da gravitaçáo universal permitiu a explicaçáo do fenômeno das marés, as correntes e ondas foram explicadas a partir das equaçōes da dinâmica, a salinidade foi explicada da mesma forma que os sedimentos marinhos e a teoria da evolução dos organismos vivos, desenvolvida a partir dos resultados da viagem de circunavegação da Terra, do navio de pesquisas Challenger, em 1872/76, deu nova interpretação a existência dos peixes, mamíferos e outros habitantes dos oceanos.

Depois da viagem do Challenger, a descriçăo dos fenômenos físicos oceânicos consagrou o nome Geografia Fisica Marinba para a disciplina que estuda a distribuiçáo geográfica das características físicas dos oceanos e a extensão dessa descriçáo às demais disciplinas básicas oceânicas, que também se estabeleciam, deu origem ao nome que se firma até hoje no cenário das ciências dos oceanos: a Oceanografia.

Na virada do século 20 , os campos magnético, elétrico e gravitacional haviam sido descritos, o elétron, e outras partículas constituintes da matéria, descobertas, juntamente com a verificação da constância da velocidade da luz, em qualquer sistema de referência do nosso Universo. $O$ elétron, o átomo, a molécula, a célula, o sistema genético foram ra- 
pidamente incorporados à linguagem da ciência que se desenvolvia, na descrição dos processos oceânicos, nos quais pontificava o fenômeno da turbulência, e a forma desordenada com que agem os fluidos na condução da energia.

Incorporando também desenvolvimentos tecnológicos, resultantes do conhecimento científico alcançado, foram construídos os batiscafos para a observação do oceano profundo, em decorrência das duas grandes guerras mundiais, que ocorreram no século XX em 1914/18 e $1939 / 45$ e, dessa forma, a terceira dimensão dos oceanos pode também ser objeto do método científico, através da observação direta.

Neste cenário foi criado, em 31 de dezembro de 1946, pelo Decreto-Lei no 16.685 do governo do estado de São Paulo $O$ Instituto Paulista de Oceanografia, subordinado à Divisão de Peixes e Animais Silvestres do Departamento de Produção Animal e, logo a seguir, com o Decreto-Lei no 16.919 de 13 de março de 1947, subordinado à Diretoria Geral do Departamento de Produção Animal da Secretaria de Agricultura, com as atribuiçóes de "estudar os fatores físicos, químicos e biológicos que influem na produtividade do mar, visando principalmente ao seu aspecto econômicon.

Com o objetivo de ter maior autonomia no cumprimento de suas funçôes de pesquisas, o Instituto foi incorporado cinco anos depois, em 4 de dezembro de 1951, à Universidade de Sáo Paulo pela Lei no 1310, passando a integrá-la como Unidade de Pesquisa e sob a denominação de Instituto Oceanográfico. Em 1960, através da Lei no 5470, o Instituto Oceanográfico conseguiu estrutura organizacional e atribuiçóes que the conferiram também a possibilidade de realizar cursos, visando à formação de oceanógrafos e técnicos.

Em 1975, o Instituto Oceanográfico sofre a transformação que the conferiu o status de Unidade de Ensino da Universidade de São Paulo, por ato do Conselho Universitário, posiçáo que ocupa até o momento.

\section{Estrutura atual}

As atividades didáticas regulares do Instituto Oceanográfico são desenvolvidas em quatro níveis:

- Graduaçáo - O Departamento de Oceanografia Física ministra o curso de habilitaçáo nessa área aos alunos do bacharelado em Física do Instituto de Física da Universidade de São Paulo. 
- Pós-Graduaçáo em Oceanografia Biológica, que conduz aos graus acadêmicos de mestre e doutor em Oceanografia Biológica e conta com cerca de 90 alunos, grande parte dos quais provenientes de diversos estados brasileiros e do exterior.

- Pós-Graduaçáo em Oceanografia Física, que conduz aos graus acadêmicos de mestre e doutor em Oceanografia Física, contando atualmente com cerca de $\mathbf{4 0}$ alunos, muitos dos quais também provenientes de diversos estados brasileiros.

- Pós-Graduação em Oceanografia Física, área de concentração Oceanografia Química e Geológica, que conta com 15 alunos, conduzindo ao título de mestre.

Para o desenvolvimento de suas atividades, o Instituto se estrutura em dois Departamentos: Departamento de Oceanografia Biológica e Departamento de Oceanografia Física.

Paralelamente aos dois Departamentos, mantém uma Divisão de Documentaçáo e Informaçáo Científica (Didc), e a Biblioteca da Instituição, responsável pelo acervo, com mais de 9750 volumes e 719 revistas periódicas correntes. Na Divisáo, são editadas regularmente as publicaçóes da Unidade: O Boletim do Instituto Oceanográfico (com seu primeiro volume publicado em 1950, atualmente circulando o número 1/2 do volume 41, correspondente a 1993); a Publicafáo Especial; o Boletim Climatológico; o Relatório Interno; e o Relatório de Cruzeiros.

Como meio para a divulgaçáo das atividades científicas dos docentes da casa e da comunidade científica em geral, são distribuídas a 684 instituiçóes congêneres, nacionais e do exterior, recebendo, em permuta, material que contribui para que o acervo de sua biblioteca seja considerado, na sua especialidade, o mais completo do Brasil.

Faz parte também da estrutura do Instituto uma flotilha que incorpora o Noc professor $W$ Besnard $(49,35 \mathrm{~m}$ de comprimento e $700 \mathrm{t})$ com acomodaçóes para 15 pesquisadores, autonomia de 20 dias, equipado com sistema de posicionamento por satélite (GPS), sonar para a localizaçáo de cardumes, CTD, correntômetros e demais instrumentos específicos para o trabalho nas diferentes áreas da Oceanografia.

As embarcaçóes Albacora e Velliger $I$, ambas com $14 \mathrm{~m}$ de comprimento dáo apoio às pesquisas costeiras realizadas pelos docentes nas bases de pesquisas, situadas nas cidades de Cananéia (Litoral Sul) e Ubatuba (Litoral Norte). 
As Bases Norte (Ubatuba - com $11.000 \mathrm{~m}^{2}$ de área) e Sul (Cananéia - com $8.500 \mathrm{~m}^{2}$ ) dispóem de ancoradouros, laboratórios, equipamento de rádio comunicação, oficinas, acomodaçóes para pesquisadores e as instalaçóes das estaçōes meteorológicas e maregráficas, cujas séries de observaçōes de $\mathbf{4 0}$ anos se encontram entre as mais longas existentes no país.

\section{Programas internacionais de pesquisa}

No que se refere à participação em programas de pesquisas em nível internacional, o IOUSP, enquanto Unidade de Pesquisas, esteve envolvido, entre outros, com as pesquisas do Ano Geofísico Internacional, em 1950, que estimulou a criação das estaçóes meteorológicas das bases de pesquisas de Cananéia e Ubatuba.

Nas atividades científicas das operaçóes da Equalant I a IV, nos anos de 1962 a 1964, a participação foi intensa na área equatorial atlântica, de onde foram obtidos os primeiros resultados sobre as correntes e a biologia da área.

Nos anos de 1974 e 1979, foram realizados os experimentos internacionais de maior monta, na área equatorial atlântica, reunindo dezenas de navios de pesquisas, juntamente com estaçóes meteorológicas terrestres, e observaçóes de satélites durante o Gate (Garp Atlantic Tropical Experiment) e durante o Fgge (First Garp Global Experiment) respectivamente. A participação do Instituto se deu através dos navios Noc Almirante Saldanba e Nhi Sirius da Diretoria de Hidrografia e Navegação, no Gate e, através do Noc professor W Besnard da USP, no Fgge, nessa ocasiáo, já como Unidade de Ensino da Universidade de Sáo Paulo.

Também como Unidade de Ensino da USP deram-se as participaçóes do Instituto no Toga (Tropical Ocean Global Atmosphere), a partir de 1983 e no Woce (World Ocean Circulation Experiment), a partir de 1986. Os programas desenvolvidos na Antártica de 1986 a 1990 encontram-se entre os mais recentes trabalhos oceanográficos realizados no Instituto através do Noc professor $W$ Besnard.

$\mathrm{Na}$ atualidade, são feitos os preparativos para o engajamento da Instituiçáo aos programas de pesquisas globais da Icsu (International Counsil of Scientific Unions), definidos pelo International Geosphere Biosphere Programme (Igbp) - Global Changes. 


\section{Programas nacionais de pesquisa}

Entre os programas de pesquisa de âmbito nacional pode-se mencionar o Gedip I e II - Grupo Executivo para o Desenvolvimento da Indústria Pesqueira, realizado de 1968 a 1972 , na região sul da costa brasileira, sob o patrocínio do governo do estado do Rio Grande do Sul; o Faunec - Fauna Nectônica da Plataforma Continental Brasileira, realizado em 1975; e o Projeto Integrado IOUSP para Uso e Exploraçáo Racional do Ambiente Marinho, com patrocínio da Finep, de 1976 a 1983, os dois últimos dedicados à regiáo costeira sudeste do estado de São Paulo; o Projeto Integrado Utilização Racional do Ecossistema Costeiro da Região Tropical Brasileira, estado de São Paulo, de 1985 a 1990; e, atualmente, o projeto Pavasas - Pontos Anfidrômicos e Variaçóes Sasonais do Atlântico Sul, com apoio do $\mathrm{CNPq}$; o projeto Opiss Oceanografia da Plataforma Interna de Sáo Sebastiăo, juntamente com o projeto Coroas - Circulação da Região Oceânica da Regiáo Oeste do Atlântico Sul, ambos apoiados pela Fapesp. Os citados, formam os grandes projetos de pesquisas já terminados ou atualmente em andamento na Instituição.

\section{Serviços de extensão}

São ministrados atualmente os cursos de atualização Fundamentos de Oceanografia, destinado aos professores de primeiro e segundo graus e o curso de difusáo cultural Noçôes sobre Oceanografia, destinado àqueles que tenham concluído o primeiro grau ou equivalente, no segundo semestre dos anos correntes.

O Instituto mantém também o Museu Oceanográfico, que contém registros históricos sobre as diferentes áreas da Oceanografia, com a finalidade de dar suporte às atividades de primeiro e segundo graus da rede de ensino, bem como à pesquisa e à extensão. Para tanto, o Museu mantém, entre outros, um serviço de empréstimo de material biológico, a alunos e professores.

\section{Pós-graduação e pesquisas}

A pós-graduação do IOUSP é um setor que merece registro, sobretudo em razáo de sua expressiva atuação na formação de mestres e doutores no cenário da Oceanografia nacional.

O programa de mestrado foi criado em 1963 através da Portaria 15, de 12 de fevereiro, nas áreas de Oceanografia Física e Oceanografia Biológica. A partir de 1972, com a reestruturaçáo dos cursos decorrentes dos novos Estatutos da USP, foi instalado o programa de dou- 
torado em Oceanografia Biológica, em 1978, e em Oceanografia Física, em 1983.

Em 1987 foi iniciado o programa de mestrado da área de concentração em Oceanografia Química e Geológica. Entre 1963 e 1993, os dois programas formaram cerca de $\mathbf{1 5 0}$ mestres e $\mathbf{7 0}$ doutores, no conjunto das três áreas de concentraçăo correspondentes aos dois Departamentos do Instituto.

Os programas de pós-graduação, através dos seus docentes orientadores, săo desenvolvidos ao longo das seguintes linhas de pesquisa:

- Oceanografia Biológica - ecossistema tropical costeiro; ecossistemas antárticos; plancton e produtividade estuarina e marinha; diversificaçăo, ciclo de vida e ocorrência de peixes estuarinos e marinhos; avaliaçáo de estoques de organismos marinhos; ecologia e sistemătica de organismos bentônicos; bioecologia de manguesais; poluição de áreas estuarinas e marinhas; aqüicultura de crustáceos.

- Oceanografia Física - oceanografia dinâmica: interaçáo ar-mar; mares: análise espectral dos processos físicos oceânicos; hidrodinâmica da plataforma continental; modelagem numérica: mares; oceanografia sinótica e dinâmica; hidrodinâmica de estuários; sensoriamento remoto; análise estatística de séries temporais oceânicas; oceanografia Antártica, circulação de larga escala.

- Oceanografia Física: área de concentraçáo Oceanografia Química e Geológica - petrografia sedimentar e mineralogia de pesados; foraminíferos recentes, distribuição e relaçôes ambientais; determinação de traços inorgânicos, polarografia de pulso; sedimentaçáo, flutuaçóes do nível do mar; sedimentaçăo marinha; sensoriamento remoto: gerenciamento costeiro; compostos orgânicos, traços em soluçóes aquosas; diagnósticos e balanços de massa químicos ambientais; sedimentaçáo costeira, processos e análise ambiental.

\section{Multidisciplinaridade e Oceanografia}

A Oceanografia é entendida, neste final do século XX, como o estudo científico da parte do planeta Terra coberta de água. Tal estudo implica descriçáo, entendimento, e previsáo dos processos de natureza física, química, geológica e biológica e de suas interaçóes, que ocorrem nos oceanos.

Neste século foram conhecidas as antipartículas, a equivalência massa/energia, a energia atômica, a particulação da energia e todas as partículas subatômicas constituintes da matéria, entre muitos outros 
eventos. A deriva dos continentes foi estabelecida firmemente, e os últimos 175 milhóes de anos de história planetária reconhecidos como registrados nos sedimentos existentes no fundo dos oceanos.

Os ciclos bio-geo-químicos foram também reconhecidos e as mudanças climáticas de escala de milhares de anos, constatadas nos sedimentos marinhos e identificadas como devidas a modificações orbitais terrestres.

Foi iniciada a era espacial, o Homem foi a Lua, estimulando uma visão holística do planeta Terra e de todos os programas globais de observação dos oceanos.

A multidisciplinaridade da Oceanografia pode ser estudada segundo as inúmeras escalas do espaço-tempo em que ocorrem, na quase solução (química) aquosa,(não fora o material particulado e a vida marinha, que vai do fentoplancton até os grandes mamíferos) os processos oceânicos.

Os processos oceânicos, em princípio, podem ser estudados multidisciplinarmente, com valores arbitrariamente estimados nas escalas das partículas elementares (dez a menos catorze do $\mathrm{cm}$ e do seg); na escala dos átomos (dez a menos onze do $\mathrm{cm}$ e a menos dez do seg); das moléculas (dez a menos dez do $\mathrm{cm}$ e a menos cinco do seg); das células e dos tecidos (dez a menos cinco do cm e do seg); da escala do Homem (do segundo até cinqüenta anos e até dez a quinta do $\mathrm{km}$ ); e escala planetária (anos e anos luz).

As escalas ocorrem simultaneamente, no espaço-tempo, sendo a escolha de uma ou mais delas, para escala de trabalho, uma limitação das atividades das institutiçōes oceanográficas existentes.

A maioria dessas instituiçóes, inclusive o Instituto Oceanográfico da USP, está equipada e concentra capacitaçáo em Ciência para o exame dos processos oceânicos, centralizada na escala do Homem, assim nominada por corresponder ao período médio da vida produtiva do ser humano - cerca de 50 anos - e estar circunscrita às dimensóes do planeta.

Na multidisciplinaridade, em todas as escalas, reconhece-se, há uma hierarquia nos estudos dos processos oceânicos que são, muitas vezes, conduzidos de forma não-simultânea. A precedência se dá às questōes de existência e unicidade, isto é, as questóes da realidade factual dos processos físicos, químicos e geológicos, que moldam, se não determinam, os processos biológicos. 
Tal hierarquia, pode-se interpretar, parece apontar para as escalas dos processos inerentes ao fenômeno da vida, as quais năo se sabe avaliar. Entretanto, com fé inabalável e com o estímulo dos progressos da ciência, obtidos até agora, acredita-se que, medindo e refletindo, conseguir-se-á chegar a esse conhecimento, decifrando-se $o$ angustiante enigma da existência, algum dia... em alguma época

Afranio Rubens de Mesquita é professor do Instituto Oceanográfico da USP. 